\title{
Monodisperse ZnO Solid Spheres by an Assisted Structure Directing Agent-Hydrothermal Method
}

\author{
S. López-Romero, M. J. Quiroz Jiménez \\ Departamento de Materia Condensada y Criogenia, Instituto de Investigaciones en Materiales, Universidad \\ Nacional Autónoma de México, México DF, México \\ Email:sebas@unam.mx
}

Received 26 September 2015; accepted 24 November 2015; published 27 November 2015

Copyright (C) 2015 by authors and Scientific Research Publishing Inc.

This work is licensed under the Creative Commons Attribution International License (CC BY). http://creativecommons.org/licenses/by/4.0/

(c) () D Open Access

\begin{abstract}
Monodisperse ZnO solid spheres nanostructures were synthesized and deposited on Si (100) silicon substrates by the hexamethylenetetramine (HMTA)-assisted hydrothermal method at high temperature $\left(200^{\circ} \mathrm{C}\right)$. In this case the HMTA is used as structure directing agent (SDA) to growth of the ZnO solid spheres. The source material used was zinc nitrate hexahydrate under a chemical reaction of hydrolysis-condensation of the $\mathrm{Zn}^{2+}$ salt aqueous solution. The structure and morphology of the ZnO solid spheres were studied by means of X-ray diffraction (XRD) and scanning electron microscopy (SEM) techniques. Furthermore, the photoluminescence (PL) of the ZnO solid spheres was measured to optical characterization of the product. The remarkable influence of the HMTA as structure directing agent and the reaction temperature to the formation of the solid spheres nanostructures is demonstrated.
\end{abstract}

\section{Keywords}

Zinc Oxide, Solid Spheres, Nanostructures, Silicon Substrate, Hydrothermal Method

\section{Introduction}

Zinc oxide is one of the most studied oxide semiconductors and recently attracting more attention due to the possibility of producing complex nanostructures by suppressing the nature polar of the $\mathrm{ZnO}$ nanocrystals. Using structure directing agents (SDAs) [1]-[9], the $\mathrm{ZnO}$ wurtzite nanocrystals have an non-center symmetric symmetry and along the (001) direction have alternatively piled $\mathrm{O}_{2}$-surface negatively charged and $\mathrm{Zn}^{2+}$ surface charged positively forming polar structures along c-axes. This polar structure plays a very important role in de- 
termining the size and morphology of the nanostructured materials: this polar property of the ZnO nanocrystals causes invariably growth preferential along the c-exes promoting the formation of 1-D nanostructures. The use of SDA in the synthesis process of $\mathrm{ZnO}$ nanocrystals promotes the growth of 3-D nanostructures. In general the nanostructures might be applied for blue semiconductor lasers due to its wide band gap (3.37 eV) and high exciton binding energy (60 meV) [10], transparent semiconductor [11], piezoelectric [12], short-wavelength lightemitting devices [13], blue emitting LEDs [14], chemical sensor [15], solar cells [16], etc. Several methods for the production of this kind of nanomaterials have been described, such as, electrodepositing [17], evaporation [18], vapor-liquid-solid (VLS) growth [19], metal organic catalyst assisted vapor-phase epitaxy [20], aqueous thermal decomposition [21], microwave activated chemical bath deposition (MW-CBD) [22], chemical bath deposition (CBD) [23], and surfactant-assisted hydrothermal method [24]. This last method is more convenient than others because it is less expensive; it has an easier composition control; the coating can be deposited on large area. However, it is important to indicate that the employed surfactant in some cases can act as structure directing agent (SDA) [25] [26], and in conjunction with the empirical theory on shape guiding and ultimate shape determination formulated by Lee and coworkers [27], it is a powerful toll to obtain nanostructures ranging from 1-D to most complex 3-D nanostructures. Next, a brief exposition on Lee theory is as follows:

Since an empirical theory suggested by Lee and coworkers [27] on shape guiding process would be of particular interest to obtain both 1-D (nanotubes, nanorods, etc.) nanostructures and other more complex shapes as triangles and diamonds. However, it also will be possible to start examining the important parameters for selective growth and ultimate shape determination including isotropic forms as cubes and spheres and anisotropic forms as tubes, rods and wires. Lee and coworkers [27] pioneers in the development of this empirical theory established that were five critical factors that could affect the selective growth and ultimate shape determination of nanostructures: 1) the crystalline phase of the seeds at the nucleation stage is determinant for directing the intrinsic phase of the nanocrystals due to its characteristic unit cell structure; potentially the seeds can have a variety of different crystallographic phases but the stable phase is highly dependent on its environment especially the temperature; 2) the growth time is alternatively a factor that plays an important role in shape control of nanostructures; 3) the delicate balance between the kinetics and thermodynamic growth regimes, in the kinetic regime fast growth on the crystallographic faces with high surface energy promotes 1-D formation. However when sufficient thermal energy is supplied either by utilizing higher growth temperatures $\left(\sim 200^{\circ} \mathrm{C}\right)$ for extended periods of time (i.e. $2 \mathrm{~h}$ at $200^{\circ} \mathrm{C}$ ) the most thermodynamically stable (spherical shapes) are favored through the intraparticle 1-D to 2-D Oswald Ripening process [28]; 4) organic capping molecules can act as structure directing agents (SDA) to determine the form of the nanostructures: the surface properties of the nanostructures can be also tailored by the types and the amounts of adsorbing organic capping molecules present in the SDAs or catalyst [1]; this SDAs can affect the intrinsic surface energy of the crystallographic face of the seeds since the kinetic energy barrier is inversely proportional to the surface energy; 5) the molecular precursor which can decompose under mild conditions is critical for kinetics growth process [2].

In this work taking account the critical factors of temperature and SDAs for shape end determination of nanostructures process disperse $\mathrm{ZnO}$ solid spheres were synthesized and deposited on $\mathrm{Si}$ (100) substrates at high temperature $\left(200^{\circ} \mathrm{C}\right)$ by an hexamethylenetetramine (HMTA)-assisted hydrothermal method. The HMTA was used as structure directing agent (SDA) in a chemical reaction hydrolysis-condensation with zinc nitrate hexahydrated $\left(\mathrm{Zn}\left(\mathrm{NO}_{3}\right)_{2} \cdot 6 \mathrm{H}_{2} \mathrm{O}\right)$. However, the growth mechanism of the $\mathrm{ZnO}$ solid spheres is explained analyzing the effect that the SDA and temperature have on the polarity of the $\mathrm{ZnO}$ crystals.

\section{Experimental}

\subsection{Materials}

All chemicals (Sigma-Aldrich) used in this study were of analytical reagent grade and used without further purification. Silicon wafers (Virginia semiconductor, Inc.) having $<100>$ orientation were used as substrates.

\subsection{Preparations of Spheres Nanostructures}

Zinc nitrate hexahydrated $\left(\mathrm{Zn}\left(\mathrm{NO}_{3}\right)_{2} \cdot 6 \mathrm{H}_{2} \mathrm{O}\right)$ was taken as the source material of zinc and hexamethylenetetramine (HMTA), also called methenamine $\left(\left(\mathrm{CH}_{3}\right)_{6} \mathrm{~N}_{4}\right)$, as structure directing agent. The chemical reactions to obtain $\mathrm{ZnO}$ using (HMTA) have been published in [29]. Briefly: the precursor was prepared by dissolving 3.0 gr of 
Zinc nitrate $\left[\mathrm{Zn}\left(\mathrm{NO}_{3}\right)_{2}\right]$ and 2.8 gr of HMTA. Deionized water under vigorous stirring at $50^{\circ} \mathrm{C}$ for $1 \mathrm{~h}$ to form a $0.01 \mathrm{M}$ equimolar solution. Then, the silicon substrates were immersed in this solution at $200^{\circ} \mathrm{C}$ for $1 \mathrm{~h}$. Finally, the substrates were washed with deionized water and allowed to dry in air at room temperature.

\section{Characterization}

Morphology and crystal structure of the samples were studied using a JEOL FEG 2010 Fast Tem electron microscope with 1.9 A resolution (point to point) equipped with a HAADF detector. The X-ray diffraction (XRD) pattern of $\mathrm{ZnO}$ nanospheres was obtained with a X-ray diffractometer (SIEMENS D 5000) using the $\mathrm{CuK}_{\alpha}$ $\left(1.5406 \AA\right.$ ) radiation, with a scanning speed of $1^{\circ} 2 \theta \mathrm{X}$ min and $35 \mathrm{KV}$ and $30 \mathrm{~mA}$.

\section{Results and Discussion}

\subsection{Structural Properties}

Figure 1 shows the XRD patterns of the ZnO solid spheres prepared by the SDA HMTA-assisted hydrothermal method and grown on Si (100) silicon substrates. It is clearly observed that in the XRD patterns all diffraction peaks were indexed to the hexagonal phase of $\mathrm{ZnO}$ having a lattice parameters a $=3.249$ and $\mathrm{c}=5.206 \AA$ (JCPD

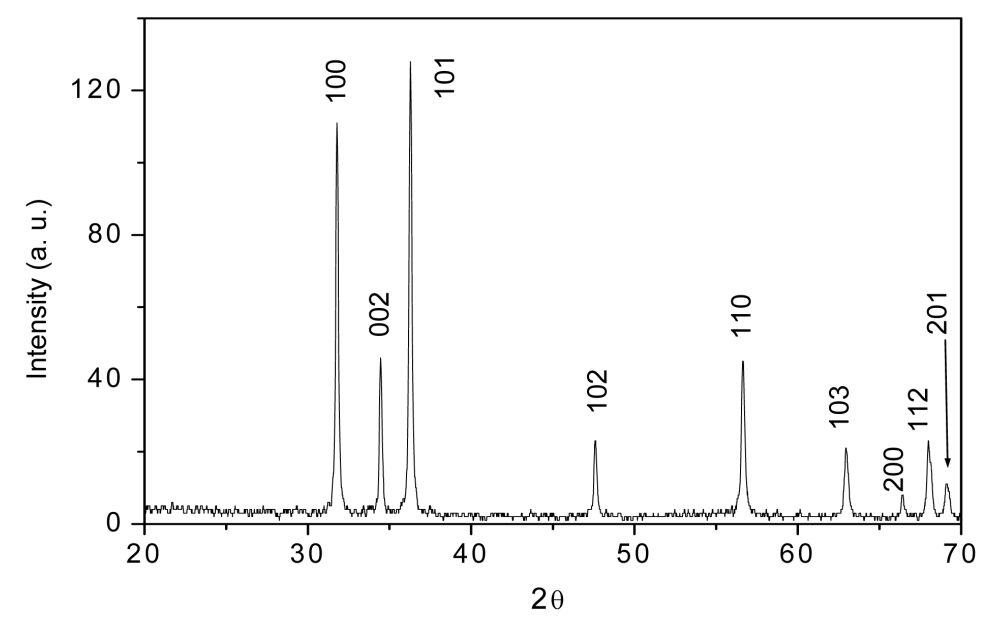

(a)

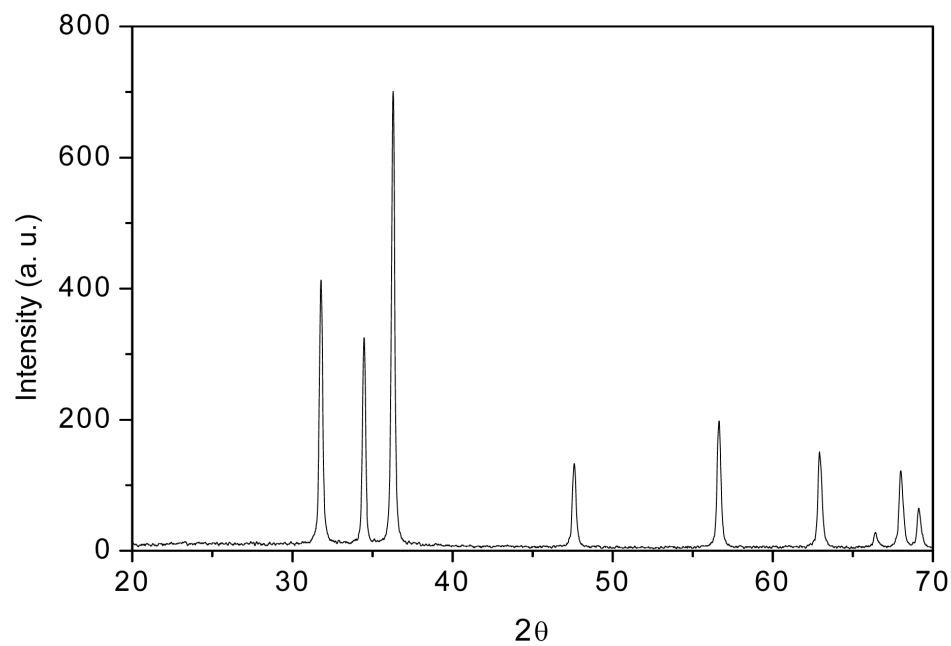

(b)

Figure 1. The X-ray diffraction pattern of the (a) ZnO solid spheres deposited on silicon substrates; (b) of the ZnO particles obtained without the SDA HMTA. 
file No. 36-1451). It is important to observe that the XRD patterns of the solid spheres showed in Figure 1. that the [002] direction is substantially suppressed and other growth directions such as [100], [101], [110], and [103] are significantly enhanced, leading to the isotropic growth of the $\mathrm{ZnO}$ solid nanospheres, also the XRD patterns do not show any preferential growth in all your (hkl) planes indicating that the crystalline form of the $\mathrm{ZnO}$ product is highly symmetric e. d. spheres. Moreover, based on the high intensity of the peaks and low half width and using Debye Scherrer formula to measure size crystal resulting to be of $80 \mathrm{~nm}$ concluding that the spheres $\mathrm{ZnO}$ nanostructures crystalize very well. Figure 1(b) shows the XRD pattern of $\mathrm{ZnO}$ particles obtained without SDA HMTA.

\subsection{Morphology}

Figure 2 shows the SEM image of the $\mathrm{ZnO}$ solid spheres grown on silicon substrates they have an approximate diameter of $0.5 \mu \mathrm{m}$. The $\mathrm{ZnO}$ spheres growth of monodisperse form. It is clearly seen that the size of the solid spheres is uniform e. d. they have similar size. To check the effect of the SDA hexamethylenetetramine on the growth of the solid spheres another hydrothermal reaction without SDA was realized under the same condition that with SDA; Figure 3 is a SEM image of the obtained product: only ZnO particles but no spheres were obtained.

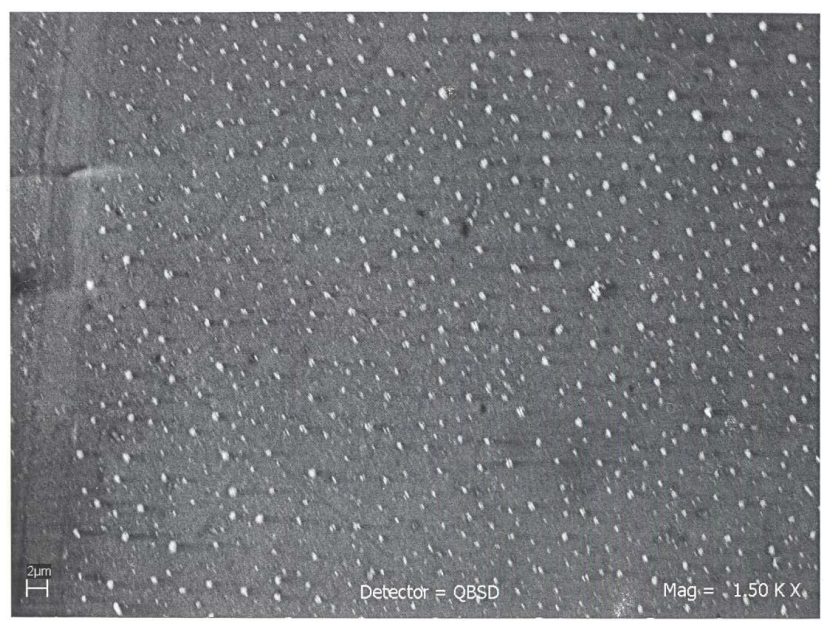

Figure 2. SEM image of the $\mathrm{ZnO}$ solid spheres obtained using HMTA as SDA and deposited on Si (100) Substrates.

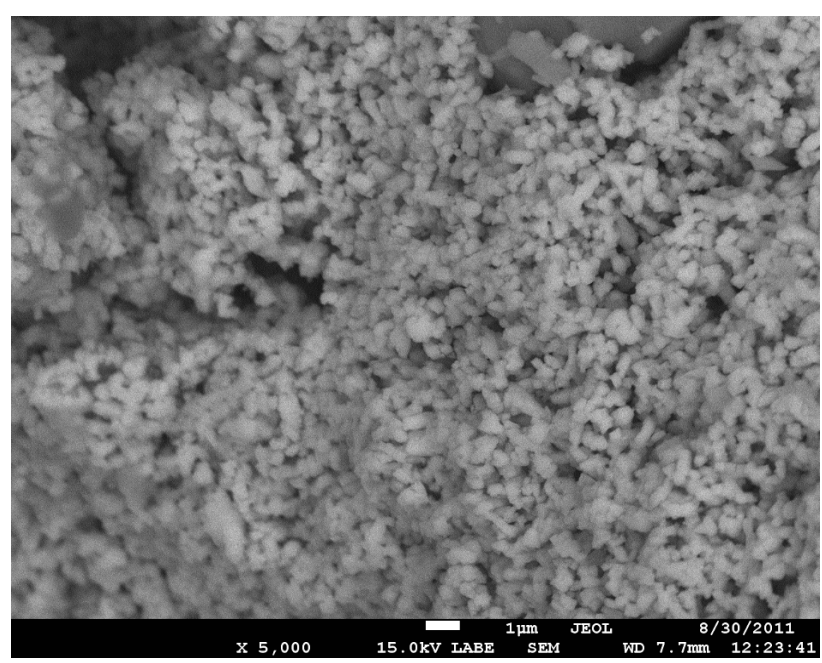

Figure 3. SEM image of the $\mathrm{ZnO}$ nanoparticles obtained without the SDA HMTA. 


\subsection{Growth Mechanism}

A possible explication for the role that play the hydrothermal reaction temperature of $200^{\circ} \mathrm{C}$ and the SDA HMTA on the growth of the symmetric solid spheres nanostructures is as follow: With respect to the growth temperature this is an clave factor to determine the final phase of the nanocrystals in general: if the growth temperature is high $\left(<200^{\circ} \mathrm{C}\right)$ the most stable phase is formed (spheres, cubes, triangles, etc.), if the growth temperature is low $\left(>200^{\circ} \mathrm{C}\right)$ nanostructures 1-D are formed [27], in our case the growth temperature was of $200^{\circ} \mathrm{C}$ therefore an sphere isotropic symmetric nanostructure was formed.

As was mentioned in the introduction the $\mathrm{ZnO}$ nanocrystals are intrinsically of polar nature; together with the polar surfaces the $\mathrm{ZnO}$ has tree fast growth directions of [0001], [0110] and [3110] that increase the anisotropic growth of 1-D nanostructures including c-exes oriented nanorods, nanowires and a-exes oriented nanobelts. At the nanometric scale for the $\mathrm{ZnO}$ the surface to volume ratio increases notably with the size reduction and the effect of the surface specially the surface polarity play a determinant role in the final formation and chemical and physical properties of the $\mathrm{ZnO}$ nanostructures, in this point it is important remember that the $\mathrm{ZnO}$ polar surfaces are responsible for the preferential growth along c-axes of the $\mathrm{ZnO}$ nanostructures and the growth of isotropic and symmetric spherical nanostructures only is possible if the SDA HMTA effectively passivated the ZnO polar surfaces leading to balanced vertical and lateral growth rate. The SDA also allowed for the control of both size and size distribution of $\mathrm{ZnO}$ spheres nanostructures.

\subsection{Photoluminescence Results}

Figure 4 shows the room temperature photoluminescence (PL) measurement of the ZnO solid spheres nanostructures, the emission spectrum was obtained using the laser line with a wavelength of $358 \mathrm{~nm}$ from an He:Cd laser as the excitation source, the emission spectrum presents the two typical emission bands centered the first about $380 \mathrm{~nm}$ and the second with a maximum centered between 500 and $530 \mathrm{~nm}$; the first band is a exciton emission band in the UV region and is caused by the radiative annihilation of excitons, the second is an intense band in the green region of the visible spectrum produced by the radiative recombination of an electron from a level in the conduction band and an deeply trapped hole in the bulk $\left(V_{0}\right)$ of an $\mathrm{ZnO}$ particle [30] [31]. However, Figure 4 shows that the intensity of the band visible is less than the intensity of exciton band, this is caused by an effect of particle size as proposed by Van Dijken, which establish that as the size of the $\mathrm{ZnO}$ particles increases the intensity of visible emission decreases and the intensity of exciton emission increase [32]. In this case, from Figure 2 the $\mathrm{ZnO}$ nanospheres size is about $0.5 \mu$ in diameter is bigger than Dijken particles resulting thus in a decreasing of the intensity of green visible respect to that of exciton emission.

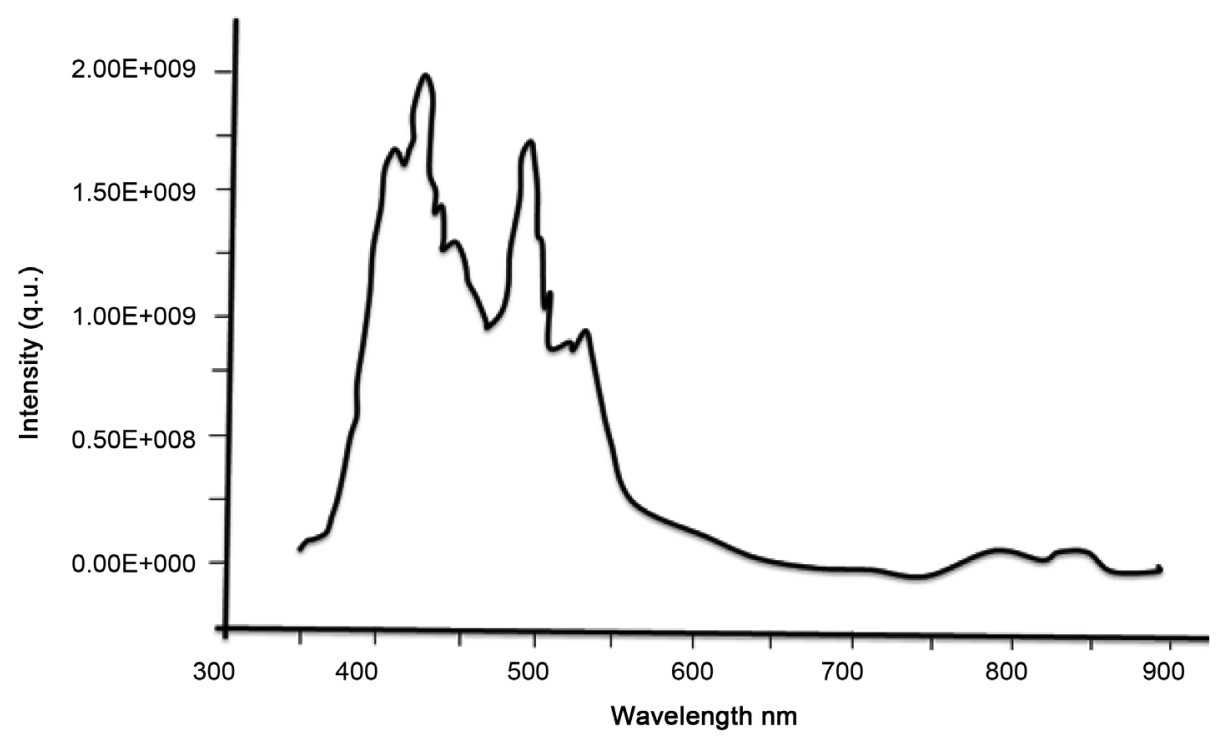

Figure 4. Room temperature photoluminescence spectra of the $\mathrm{ZnO}$ Solid spheres nanostructures exited with an wavelength of $358 \mathrm{~nm}$. 


\section{Conclusion}

In this work $\mathrm{ZnO}$ solid spheres nanostructures were synthesized by structure directing agent-assisted hydrothermal method on silicon substrates, and the SDA used was HMTA. The SEM results demonstrated that the solid spheres nanostructures of average size of $0.5 \mu$ were obtained. X-ray studies showed that the solid spheres were single crystals having the ZnO hexagonal phase. The role played by the SDA NMTA is essential to obtain the solid spheres; your direct action is suppressing the influence of the polar surfaces since this influence causes preferential growth along c-axes of the $\mathrm{ZnO}$ nanostructures.

\section{Acknowledgements}

The authors wish to thank to Adriana Tejeda (IIM) for the XRD measurements. To Omar Novelo Peralta (IIM), Carlos Flores (IIM) and Luis Rendón (IF) for their support in the SEM and TEM characterization. The authors are also thankful to the Central Microscopy facilities of the Institute of Physics, UNAM, for providing the microscope tools used in this work.

\section{References}

[1] Foe, K., Namkoong, G., Abdel-Fattah, T.M., Baumgart, H., Jeong, M.S. and Lee, D.-S. (2013) Controlled Synthesis of ZnO Spheres Using Structure Directing Agents. Thin Solid Films, 534, 76-82. http://dx.doi.org/10.1016/j.tsf.2013.01.105

[2] Yi, G.-R., Moon, J.H., Manoharan, V.N., Pine, D.J. and Yang, S.-M. (2002) Packings of Uniform Microspheres with Ordered Macropores Fabricated by Double Templating. Journal of the American Chemical Society, 124, 13354-13355. http://dx.doi.org/10.1021/ja027325v

[3] Song, J.-S., Tronc, F. and Winnik, M.A. (2004) Two-Stage Dispersion Polymerizacion toward Monodisperse, Controlled Micrometer-Sized Copolymer Particles. Journal of the American Chemical Society, 126, 6562-6563. http://dx.doi.org/10.1021/ja048862d

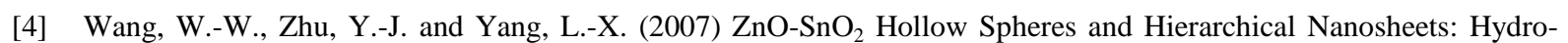
thermal Preparation, Formation Mechanism, and Photocatalytic Properties. Advanced Functional Materials, 17, 59-64. http://dx.doi.org/10.1002/adfm.200600431

[5] Jiang, H., Hu, J.Q., Gu, F. and Li, C.Z. (2008) Large-Scaled, Uniform, Monodispersed ZnO Colloidal Microspheres. Journal of Physical Chemistry C, 112, 12138-12141. http://dx.doi.org/10.1021/jp8024232

[6] Yan, Z.J., Ma, Y.W., Wang, D.L., Wang, J.H., Gao, Z.S. and Song, T. (2008) Surfactant-Free Fabrication of ZnO Spheres and Pseudospherical Structures. Journal of Physical Chemistry C, 112, 9219-9222. http://dx.doi.org/10.1021/jp8013173

[7] Bai, S.-N., Shieh, J.-S. and Tseng, T.-Y. (1995) Characteristic Analysis of ZnO Varistors Made with Spherical Precipitation Powders. Materials Chemistry and Physics, 41, 104-109. http://dx.doi.org/10.1016/0254-0584(95)80014-X

[8] Liu, J.P., Huang, X.T., Li, Y.Y., Zhong, Q. and Ren, L. (2005) Preparation and Photoluminescence of ZnO Complex Structures with Controlled Morphology. Materials Letters, 60, 1354-1359. http://dx.doi.org/10.1016/j.matlet.2005.11.056

[9] Zhang, H., Yang, D.R., Li, S.Z., Ma, X.Y., Ji, Y.J., Xu, J. and Que, D.L. (2005) Controllable Growth of ZnO Nanostructures by Citric Acid Assisted Hydrothermal Process. Materials Letters, 59, 1696-1700. http://dx.doi.org/10.1016/j.matlet.2005.01.056

[10] Huang, M.H., Mao, S., Feick, H., Yan, H.Q., Wu, Y.Y., Kind, H., Weber, E., Russo, R. and Yang, P.D. (2001) RoomTemperature Ultraviolet Nanowire Nanolasers. Science, 292, 1897-1899. http://dx.doi.org/10.1126/science.1060367

[11] Hu, J.H. and Gordon, R.G. (1992) Atmospheric Pressure Chemical Vapor Deposition of Gallium Doped Zinc Oxide Thin Films from Diethyl Zinc, Water, and Triethyl Gallium. Journal of Applied Physics, 72, 5381. http://dx.doi.org/10.1063/1.351977

[12] Pompe, T., Srikan, V. and Clarke, D.R. (1996) Acoustoelectric Current Saturation in c-Axis Fiber-Textured Polycrystalline Zinc Oxide Films. Applied Physics Letters, 69, 4065. http://dx.doi.org/10.1063/1.117819

[13] Bagnall, D.M., Chen, Y., Zhu, Z., Yao, T., Koyama, S., Shen, M.Y. and Goto, T. (1997) Optically Pumped Lasing of ZnO at Room Temperature. Applied Physics Letters, 70, 2230. http://dx.doi.org/10.1063/1.118824

[14] Guo, X.L., Choi, J.H., Tabata, H. and Kawai, T. (2001) Fabrication and Optoelectronic Properties of a Transparent ZnO Homostructural Light-Emitting Diode. Japanese Journal of Applied Physics, 40, L77. http://dx.doi.org/10.1143/JJAP.40.L177 
[15] Zhang, Y.S., Yu, K., Jiang, D.S., Zhu, Z.Q., Geng, H.R. and Lou, L.Q. (2005) Zinc Oxide Nanorod and Nanowire for Humidity Sensor. Applied Surface Science, 242, 212-217. http://dx.doi.org/10.1016/j.apsusc.2004.08.013

[16] Matsui, M., Hashimoto, Y., Funabiki, K., Jim, J.-Y., Yoshida, T. and Minoura, H. (2005) Application of Near-Infrared Absorbing Heptamethine Cyanine Dyes as Sensitizers for Zinc Oxide Solar Cell. Syntetic Metals, 148, 147-153. http://dx.doi.org/10.1016/j.synthmet.2004.09.026

[17] Pauporté, T. and Lincot, D. (1999) Heteroepitaxial Electrodeposition of Zinc Oxide Films on Gallium Nitride. Applied Physics Letters, 75, 3817. http://dx.doi.org/10.1063/1.125466

[18] Mikami, M., Eto, T., Wang, J.F., Masa, Y. and Issiki, M. (2005) Growth of Zinc Oxide by Chemical Vapor Transport. Journal of Crystal Growth, 276, 389-392. http://dx.doi.org/10.1016/j.jcrysgro.2004.11.431

[19] Levitt, A.P. (1970) Whisquer Technology. Wiley-Interscience, New York.

[20] Park, W.I., Kim, D.H., Jung, S.-W. and Yi, G.-C. (2002) Metalorganic Vapor-Phase Epitaxial Growth of Vertically Well-Aligned ZnO Nanorods. Applied Physics Letters, 80, 4232. http://dx.doi.org/10.1063/1.1482800

[21] Vayssieres, L., Keis, K., Lindquist, S.-E. and Hagfeldt, A. (2001) Purpose-Built Anisotropic Metal Oxide Material: 3D Highly Oriented Microrod Array of ZnO. The Journal of Physical Chemistry B, 105, 3350-3352. http://dx.doi.org/10.1021/jp010026s

[22] Wang, W.-W. and Zhu, Y.-J. (2004) Shape-Controlled Synthesis of Zinc Oxide by Microwave Heating Using an Imidazolium Salt. Inorganic Chemical Communications, 7, 1003-1005. http://dx.doi.org/10.1016/j.inoche.2004.06.014

[23] Zhung, J., Sun, L.D., Liao, C.S. and Yan, C.H. (2002) A Simple Route towards Tubular ZnO. Chemical Communications, No. 3, 262-263. http://dx.doi.org/10.1039/b108863g

[24] Wei, H.Y., Wu, Y.S., Lun, N. and Hu, C.X. (2005) Hydrothermal Synthesis and Characterization of ZnO Nanorods. Materials Science and Engineering A, 393, 80-82. http://dx.doi.org/10.1016/j.msea.2004.09.067

[25] Molahasani, N., Sadjadi, M.S. and Zare, K. (2013) Correlation of Morphology and Luminescent Properties of ZnO Nano Particles to Different Surfactants via Hydrothermal Method. International Journal of Nano Dimension, 4, 161166.

[26] Zhang, J., Liu, H., Wang, Z. and Ming, N. (2007) Polyvinylpyrrolidone-Directed Crystallization of ZnO with Tunable Morphology and Bandgap. Advanced Functional Materials, 17, 3897-3905. http://dx.doi.org/10.1002/adfm.200700734

[27] Lee, S.-M., Cho, S.-N. and Cheon, J. (2003) Anisotropic Shape Control of Colloidal Inorganic Nanocrystals. Advanced Materials, 15, 441-444. http://dx.doi.org/10.1002/adma.200390102

[28] Baldan, A. (2002) Review Progress in Oswald Ripening Theories and Their Applications to Nikel-Base Superallops. Part 1 Oswald Ripening Theories.

[29] López-Romero, S. and Morales Leal, F. (2011) $\mathrm{Fe}_{2} \mathrm{O}_{3} / \mathrm{ZnO}$ Composite Particles Prepared by a Two-Step Chemical Soft Method. Revista Mexicana de Física, 57, 236-240.

[30] Music, S., Saric, A. and Popovic, S. (2008) Dependence of the Microstructural Properties of ZnO Particles on Their Synthesis. Journal of Alloys and Compounds, 448, 277-283. http://dx.doi.org/10.1016/j.jallcom.2006.10.021

[31] Monticone, S., Tufeu, R. and Kanaev, A.V. (1998) Photoluminescence Behavior of Purpose-Built ZnO Arrays on Different Growth Substrates. Journal of Physics and Chemistry B, 102, 2854-2862. http://dx.doi.org/10.1021/jp973425p

[32] Van Dijken, A., Meulenkamp, E.A., Vanmaekelberggh, D. and Meijerink, A. (2000) The Luminescence of Nanocrystaline ZnO Particles: The Mechanism of the Ultraviolet and Visible Emission. Journal of Luminescence, 87-89, 454456. http://dx.doi.org/10.1016/S0022-2313(99)00482-2 